\title{
Combining the Ras Inhibitor Salirasib and Proteasome Inhibitors: A Potential Treatment for Multiple Myeloma
}

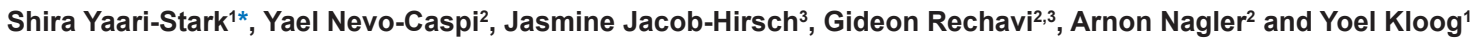 \\ ${ }^{1}$ Department of Neurobiology, The George S. Wise Faculty of Life Sciences, Tel-Aviv University, Tel-Aviv, Israel \\ ${ }^{2}$ Sheba Cancer Research Center and Guy Weinstock Multiple Myeloma Foundation, Division of Hematology, Israel \\ ${ }^{3}$ The David and Inez Myers Laboratory for Genetic Research, Department of Human Genetics, Sheba Medical Center, Tel Hashomer, and Sackler Faculty of Medicine, \\ Tel-Aviv University, Tel-Aviv, Israel
}

\begin{abstract}
Multiple myeloma (MM) is an incurable disease that develops resistance to chemotherapy. New treatments with thalidomide or bortezomib are partially successful. Drug resistance, differentiation block, and increased survival in MM result from genomic alterations, including high overexpression of cyclin $D$ and fibroblast growth factor receptor 3 (FGFR3) and mutations in NRas. Oncogenic Ras isoforms can be inhibited by the Ras inhibitor farnesylthiosalicylic acid (FTS, salirasib), which also inhibits fibroblast growth factor (FGF)-stimulated Ras activation.

Here we compared the effects of FTS on the proliferation of NCIH929 (harboring oncogenic NRas) and of two other MM cell lines, MM.1S and U266, which do not harbor oncogenic NRas. NCIH929 responded significantly better than the other cell lines to FTS treatment. FTS also inhibited FGF-stimulated GTP loading of wild-type NRas, and hence ERK activation, in MM-NCIH929. Gene-expression analysis of FTS-treated NCIH929 cells demonstrated downregulation of FGFR3, and the FGFR3 protein in these cells declined after FTS treatment. Combined treatment with FTS and the proteasome inhibitor MG132 or bortezomib yielded synergistic inhibition of NCIH929 MM cell growth.
\end{abstract}

These data strongly suggest that FGFR3 acts together with NRas to activate the MAPK pathway, and that inhibition of Ras by FTS affects both early Ras-dependent signaling and long-term Ras-dependent control of gene expression and protein translation. We suggest that salirasib be considered, both alone and in combination with proteasome inhibitors, as a potential treatment for MM.

Keywords: Multiple myeloma; Ras; FTS; Salirasib; Velcade; Bortezomib

Abbrevations: MM: Multiple myeloma; FGFR3: Fibroblast growth factor receptor 3; FTS: Farnesylthiosalicylic acid; FGF: Fibroblast growth factor

\section{Introduction}

Multiple myeloma (MM) is a progressive and almost always incurable disorder of mature B lymphocytes [1,2]. It accounts for $10 \%$ of all hematologic malignancies worldwide [2]. Typical of MM is overgrowth of plasma cells in the bone marrow, crowding out the normal blood-forming cells and thus leading to severe organ damage and other complications. As tumors grow, they invade the solid tissue that comprises the hard outer part of the bone. In most cases the myeloma cells spread into the cavities of all the large bones of the body, forming multiple small lesions, hence the name "multiple" myeloma [2].

Drug resistance, differentiation block, and increased survival in MM result from genomic alterations. The three partner chromosome regions that are most commonly involved are 11q13 (cyclin D), 4p16 (fibroblast growth factor receptor 3, FGFR3) and 16q23 (c-maf), resulting in high cyclin D and FGFR3 and mutations in NRas [3-7]. Interactions between myeloma cells and stromal cells in the tumor microenvironment results in secretion of interleukin-6 (IL-6), insulin-like growth factor 1, and vascular endothelial growth factor, each of which plays a major role in MM resistance [8]. In particular, activation of NF-kB-mediated upregulation of IL-6 secretion by stromal cells is associated with signal transduction of the Ras oncogene pathway $[9,10]$. Activating (gain-of-function) mutations of Ras have been reported in $30 \%$ to $50 \%$ of MM cases. KRas and NRas are the most frequently mutated $[3,8]$. Tumors with translocation of $(4 ; 14)$ (p16.3;q32) [11,12] can harbor activating mutations of FGFR3 or Ras, but these events appear to be mutually exclusive, suggesting that the activating mutations of these two genes have similar effects [13]. FGFR3 is one of four high-affinity tyrosine kinase receptors for the fibroblast growth factor (FGF) family of ligands. It is normally not expressed in plasma cells but can be expressed ectopically in them as a result of a translocation affecting its gene. Signaling from FGFR3 in MM results in phosphorylation of STAT3 and MAPK $[9,14]$. Activating mutations of the $\mathrm{t}(4 ; 14)$ translocated FGFR3 allele are detected in one-third of MM cell lines and in some patients, substantiating an oncogenic role for FGFR3 in MM $[9,14]$.

Standard treatments for MM comprise combinations of steroids and chemotherapeutic drugs, e.g. MP (melphalan + prednisolone) or VAD (vincristine + doxorubicin + dexamethasone) [1,2]. Although

${ }^{*}$ Corresponding author: Shira Yaari, Department of Neurobiology, The George S Wise Faculty of Life Sciences, Tel-Aviv University, 69978 Tel-Aviv, Israel, Tel: 972 52 4333462; Fax: 9723640 7643; E-mail: shira.yaari1@gmail.com

Received June 07, 2011; Accepted October 22, 2011; Published October 24, 2011

Citation: Yaari-Stark S, Nevo-Caspi Y, Jacob-Hirsch J, Rechavi G, Nagler A, et al. (2011) Combining the Ras Inhibitor Salirasib and Proteasome Inhibitors: A Potential Treatment for Multiple Myeloma. J Cancer Sci Ther 3: 187-194. doi:10.4172/19485956.1000086

Copyright: (c) 2011 Yaari-Stark S, et al. This is an open-access article distributed under the terms of the Creative Commons Attribution License, which permits unrestricted use, distribution, and reproduction in any medium, provided the original author and source are credited. 
most myeloma patients respond to such approaches at least initially, the pre-existence or emergence of drug-resistant cells represents a formidable barrier to a cure, and thus MM is nearly always an incurable disease [1]. The failure of conventional chemotherapy, coupled with the complex pathogenesis of the disease, has spurred research on novel therapeutic agents for MM. These efforts led to the development of the $26 \mathrm{~S}$ proteasome inhibitor bortezomib $\left(\right.$ Velcade $\left.^{\circledR}\right)$ [2,15-20]. Thalidomide and its analogs, including lenalidomide (Revimid), are other examples of new drugs for MM [2,15-20]. In an attempt to inhibit processing of Ras proteins, moreover, MM cell lines with wellcharacterized mechanisms of drug resistance were analyzed for their response to farnesyltransferase inhibitors (FTIs), with partial success $[8,21]$.

We have previously described the profiling of the MM cell line NCIH929 that expresses oncogenic NRas [22-24] and found, as expected $[9,14]$, marked levels of expression of FGFR3 $[25,26]$. The purpose of the present study was to examine the effect(s) of Ras inhibition induced by farnesylthiosalicylic acid (FTS, salirasib) on myeloma cell growth and survival. Here we investigated the efficacy of FTS, alone and in combination with other chemotherapeutic agents, on the growth of three MM cell lines, namely MM.1S, U266, and NCIH929 (see Table 1).

\section{Materials and Methods}

\section{Cell lines and reagents}

The human MM cell lines NCIH929 and U266 were purchased from the American Type Culture Collection (ATCC) and grown according to the ATCC protocol. Human multiple myeloma MM.1S cells were grown in RPMI 1640 medium with $10 \%$ fetal calf serum (FCS). FTS (Concordia Pharmaceuticals, Fort Lauderdale, FL) was prepared as described in detail previously [27]. Carbobenzoxy-Lleucyl-L-leucinal Z-LLL-CHO (MG132) was from Calbiochem (La Jolla, CA). Bortezomib was purchased from Johnson \& Johnson (New Brunswick, NJ). Doxorubicin hydrochloride was from Sigma-Aldrich (St. Louis, MO). Recombinant human FGF basic was from R\&D Systems (Minneapolis, MN). An enhanced chemiluminescence kit was purchased from Amersham (Arlington Heights, IL). Mouse anti-panRas antibody (Ab-3) was from Calbiochem; mouse anti-c-Myc (C-33), rabbit anti-ERK (C-14) and mouse anti-FGFR3 Abs (B-9) were from Santa Cruz Biotechnology (Santa Cruz, CA); mouse anti-phosphoERK, mouse anti-NRas and rabbit anti-tubulin (AK-15) Abs were from Sigma-Aldrich; rabbit anti-phospho-Akt (ser473) and rabbit anti-Akt Abs were from Cell Signaling (Beverly, MA). Peroxidase-goat antirabbit IgG and peroxidase-goat anti-mouse IgG were from Jackson ImmunoResearch Laboratories (West Grove, PA). Protein bands were quantified by densitometry with Image Master VDS-CL (Amersham Pharmacia Biotech, Piscataway, NJ) using TINA 2.0 software (Ray Tests).

\section{Cell growth under FTS treatment}

NCIH929, MM.1S, and U266 cells were plated in 5\% FCS medium at a density of $2 \times 10^{4}$ cells/well in 96-well plates and then treated, $3 \mathrm{~h}$ after plating, with $3-100 \mu \mathrm{M}$ FTS or vehicle (0.1\% DMSO). Apparent cell numbers were estimated by the alamarBlue assay (Serotec, Oxford, UK) according to the manufacturer's instructions. Each experiment was performed twice in quadruplicate.

For treatment of NCIH929 cells with the new FTS derivates, the latter were first dissolved in DMSO and diluted with 5\% FCS medium to a final concentration ranging from 3 to $100 \mu \mathrm{M}$. The cells were then plated, as described above, and treated with the prepared solutions or, as a control, with the vehicle (0.1\% DMSO). After 4 days, cell viability was determined with the alamarBlue reagent.

The growth-inhibition experiments were designed according to previous data and carried out with careful calibrations. MG132, alone or in combination, was applied for $30 \mathrm{~min}$ then washed out. This was sufficient to induce cell growth inhibition, as described below. More prolonged treatment with MG132 was toxic.

For the drug combination experiments in which we used the proteasome inhibitor MG132, NCIH929 cells were plated at a density of $1.5 \times 10^{6}$ in 24-well plates in 5\% FCS medium and then treated for 30 min with MG132 $(0.5,1.0$, and $2.5 \mu \mathrm{M})$. Cells were then washed, replenished with $50 \mu \mathrm{M}$ or $75 \mu \mathrm{M}$ FTS or the vehicle (0.1\% DMSO) for an additional 3 days, and counted. Alternatively, NCIH929 cells were plated at a density of $0.5 \times 10^{6}$ in 24 -well plates in 5\% FCS medium and then treated with FTS derivatives or bortezomib $(2.5 \mathrm{nM})$.

In experiments with doxorubicin $(0.1,0.25$, or $0.5 \mu \mathrm{M})$, we plated 150,000 cells in 96-well plates in 5\% FCS medium and then added 50 $\mu \mathrm{M}$ or $75 \mu \mathrm{M}$ FTS or the vehicle (0.1\% DMSO). Cells were incubated for 5 days and live cells were then assayed with alamarBlue. Each experiment was performed three times. Data obtained in these and in all subsequent experiments were analyzed statistically (see below). To assess the synergism of the combined effect of two drugs, we compared the effect of the drug combination to the product of individual fractional effects. This method is known as the fractional product method of Webb [28].

All experiments, including those with untreated controls, were performed in quadruplicate.

\section{BrdU cell proliferation assay}

NCIH929, MM.1S, and U266 cells were plated in 5\% FCS medium at a density of $2 \times 10^{4}$ cells/well in 96-well plates. After $3 \mathrm{~h}$ the cells were treated with 50,75 , or $100 \mu \mathrm{M}$ FTS or vehicle (0.1\% DMSO). BrdU staining of cells, indicating cell proliferation, was detected with the aid of the BrdU cell-proliferation assay kit (Calbiochem).

\section{Western blot analysis}

NCIH929, MM.1S, and U266 cells were plated in 5\% serum at a density of $1 \times 10^{6}$ cells/ml. FTS $(75 \mu \mathrm{M})$ or vehicle $(0.1 \%$ DMSO $)$ was added $3 \mathrm{~h}$ after plating. Cells were maintained under these conditions for $72 \mathrm{~h}$, and then lysed as described in detail elsewhere [29].

\section{Ras-GTP assays}

NCIH929, MM.1S, and U266 cells $\left(1 \times 10^{6} \mathrm{cells} / \mathrm{ml}\right)$ were plated in $25-\mathrm{cm}^{2}$ flasks in a total volume of $5 \mathrm{ml}$ in 5\% FCS medium. After $3 \mathrm{~h}$ the cells were treated with $75 \mu \mathrm{M}$ FTS or vehicle ( $0.1 \%$ DMSO). After $72 \mathrm{~h}$ of drug treatment, cells were collected and lysed in $0.2 \mathrm{ml}$ of Ras-binding domain (RBD) lysis buffer [30] containing $0.1 \mathrm{mM}$ orthovanadate. In experiments in which NCIH929 cells $\left(2 \times 10^{6}\right.$ cells $\left./ \mathrm{ml}\right)$ were grown in serum-free medium, FTS $(2.5 \mu \mathrm{M})$ or the vehicle $(0.1 \%$ DMSO) was added 1 day later. Lysates containing $250-500 \mu$ g protein were analyzed for Ras-GTP by the glutathione S-transferase (GST)-RBD pull-down assay. This was followed by western immunoblotting with mouse antipan Ras Ab as described elsewhere [29], as well as with mouse antiNRas, and mouse anti-phospho ERK. 
Citation: Yaari-Stark S, Nevo-Caspi Y, Jacob-Hirsch J, Rechavi G, Nagler A, et al. (2011) Combining the Ras Inhibitor Salirasib and Proteasome Inhibitors: A Potential Treatment for Multiple Myeloma. J Cancer Sci Ther 3: 187-194. doi:10.4172/1948-5956.1000086

\section{Real-time PCR for determination of FGFR3 expression levels}

FGFR3 expression was monitored by real time quantitative PCR (RT-PCR) with the aid of the ABI 7900 Genetic Analyzer. Primers specific for FGFR3 were used to monitor FGFR3 expression, and GAPDH primers were used to monitor the expression of GAPDH as a normalizing gene. Reactions were carried out with the SYBR Green PCR Master Mix (Applied Biosystems, Carlsbad, CA). The primers used for FGFR3 were: forward, 5' GACGTCCACCGACGAGTAC; reverse, 5' GGCAAACACGGAGTCGTCC. The primers used for GAPDH were: forward, 5' TGGACCTCATGGCCCACA; reverse, 5' TCAAGGGGTCTACATGGCAA.

\section{Statistical analysis}

Results were analyzed by the Mann-Whitney U test, a nonparametric test.

\section{Results}

\section{Growth inhibition of MM cell lines by the Ras inhibitor FTS}

We first compared the effects of FTS on the proliferation of $\mathrm{NCIH} 929$ cells possessing both oncogenic NRas(13V) and c-Myc to its effects on two other myeloma cell lines, MM.1S and U266, which do not express oncogenic Ras. Genetic characteristics of each of these cell lines are described in Table 1.

To assay cell proliferation we measured BrdU incorporation into the DNA of cells treated for $24 \mathrm{~h}$ with FTS $(50,75$, or $100 \mu \mathrm{M})$. In a separate set of experiments we analyzed the effect of FTS on cell growth by counting cells stained with alamarBlue (see Methods). The results of both sets of experiments indicated that all three cell lines were affected by FTS, with the most significant effect being recorded in NCIH929 cells (Figure 1). In both assays the $\mathrm{IC}_{50}$ values recorded were $64 \mu \mathrm{M}$ for NCIH929, $82 \mu \mathrm{M}$ for MM.1S, and 82-100 $\mu \mathrm{M}$ for U266.

These results led us to measure the amounts of active NRas (NRasGTP) in each of the MM cell lines and then examine the effects of FTS on these amounts. Active Ras was measured with the RBD pull-down assay. Of the three MM cell lines, NCIH929 cells expressed the highest levels of both total and active Ras (Figure 1B, left panel). Treatment with FTS caused a significant reduction in total Ras and NRas-GTP in NCIH929 but not in the two other cell lines, in which the amounts of active Ras were low (Figure 1B, right panel). These findings suggested that the relatively stronger inhibition of cell proliferation by FTS recorded

\begin{tabular}{|l|l|l|l|}
\hline Cell line & NCIH929 & MM.1S & U266 \\
\hline Tissue & Bone marrow & Peripheral blood & Peripheral blood \\
\hline Cell type & $\begin{array}{l}\text { B lymphocyte } \\
\text { IgA kappa }\end{array}$ & $\begin{array}{l}\text { B lymphocyte } \\
\text { IgA lambda }\end{array}$ & $\begin{array}{l}\text { B lymphocyte } \\
\text { IgE lambda }\end{array}$ \\
\hline Positive for & $\begin{array}{l}\text { PCA1 } \\
\text { Transferrin receptor } \\
\text { CD38 }\end{array}$ & $\begin{array}{l}\text { PCA1 } \\
\text { HLA-DR } \\
\text { CD38, CD59; CD52 } \\
\text { ILR2 }\end{array}$ & \\
\hline $\begin{array}{l}\text { Unique } \\
\text { characteristics }\end{array}$ & $\begin{array}{l}\text { NRas active; } \\
\text { Amplified } c-M y c ; \\
\text { Overexpression of } \\
\text { t(4;14) and FGFR3 }\end{array}$ & $\begin{array}{l}\text { c-Maf over- } \\
\text { expression; } \\
\text { Sensitive to } \\
\text { dexamethasone }\end{array}$ & $\begin{array}{l}\text { Produces IL-6; } \\
\text { High STAT3 } \\
\text { levels; } \\
\text { Resistant to Fas }\end{array}$ \\
\hline
\end{tabular}

Data are according to ATCC

Ig, immunoglobulin; PCA1, plasma cell-associated antigen; HLA-DR, D-related human leukocyte antigen; FGFR3, fibroblast growth factor receptor 3; IL-6, interleukin 6; STAT3, signal transducers and activators of transcription 3

Table 1: Comparison of the characteristics of three myeloma cell lines.
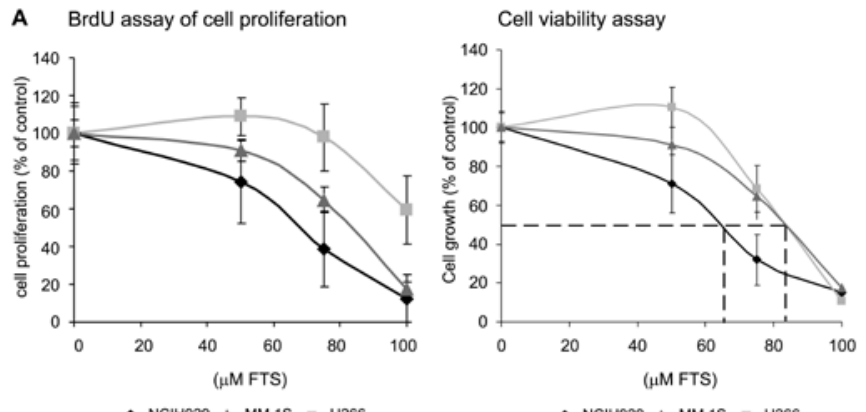

B

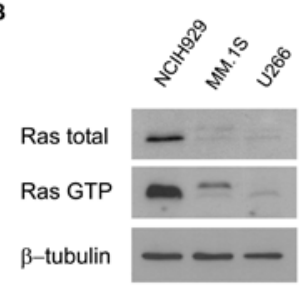

$\rightarrow$ NCIH929 $₫$ MM.1S - - U266

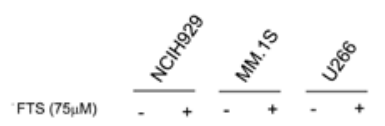

Ras total

Ras GTP

NRas GTP

$\beta-$ tubulin

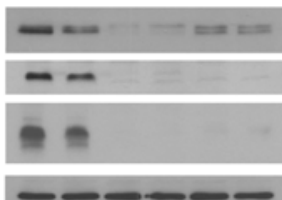

\section{C $\mathrm{NClH} 929$}

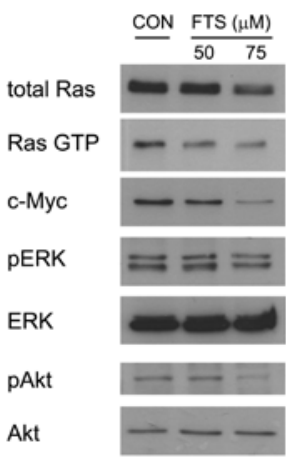

Figure 1: Inhibition of growth of MM cell lines by the Ras inhibitor FTS. (A) Cells $\left(2 \times 10^{4}\right.$ cells/well in 96-well plates) were plated and treated with 75 $\mu \mathrm{M}$ FTS or vehicle (control) for $48 \mathrm{~h}$ in $5 \%$ FCS medium. Cells were stained with $\mathrm{BrdU}$ for determination of reduction in proliferation (means $\pm \mathrm{SD}, n=$ 3 , left panel. $P<0.05$ for NCIH929 and MM.1S, and $P>0.05$ for U266). In another experiment, cell viability was assayed with the aid of the alamarBlue reagent (means $\pm \mathrm{SD}, n=3$, right panel). (B) FTS reduces total Ras, active Ras, and NRas in NClH929 but not in MM.1S or U266 MM cell lines. Cells (1 $\times 10^{6} \mathrm{cell} / \mathrm{ml}$ ) were grown in $5 \%$ FCS medium for $72 \mathrm{~h}$ and then lysed (left panel). Alternatively, cells $\left(1 \times 10^{6} \mathrm{cells} / \mathrm{ml}\right)$ were plated in $5 \%$ FCS medium and treated with $75 \mu \mathrm{M}$ FTS or vehicle (control) for $72 \mathrm{~h}$ and then lysed (right panel). Ras activity was determined by a GTP-Ras pull-down assay followed by western blotting with anti-pan-Ras or anti-NRas antibodies. The amounts of Ras and $\beta$-tubulin were quantitatively analyzed by western immunoblotting. Typical immunoblots visualized by ECL are shown $(n=3)$. (C) Ras downstream effectors are inhibited by FTS in NCIH929 cells. NCIH929 cells were grown and treated as described in B. Active Ras, total Ras, c-Myc, p-ERK, ERK, p-Akt, and Akt were quantitatively analyzed by western immunoblotting. FTS at $75 \mu \mathrm{M}$ reduced the amount of proteins by $56 \pm 4 \%$ for Ras-GTP, $41.8 \pm 7 \%$ for total Ras, $65 \pm 2 \%$ for c-Myc, $38 \pm 5 \%$ for pERK, and $52 \pm 1.6 \%$ for pAkt in (means $\pm \mathrm{SD}, n=3$ )

in NCIH929 may be due to a mechanism for enhanced sensitivity to downregulation of active NRas in these cells. The significantly stronger effect of FTS observed in cancer cells harboring oncogenic Ras than in those harboring wild-type (wt) Ras is a typical response of human cell lines to this Ras inhibitor, which exhibits selectivity towards the active (GTP-bound) form of Ras proteins [31-33]. In addition to the 
Citation: Yaari-Stark S, Nevo-Caspi Y, Jacob-Hirsch J, Rechavi G, Nagler A, et al. (2011) Combining the Ras Inhibitor Salirasib and Proteasome Inhibitors: A Potential Treatment for Multiple Myeloma. J Cancer Sci Ther 3: 187-194. doi:10.4172/1948-5956.1000086

reduction in both total and active Ras in the FTS-treated NCIH929 cells, we observed a significant decrease in the amounts of c-Myc and p-Akt, but not in p-ERK, in the presence of $75 \mu \mathrm{M}$ FTS (Figure 1C). These results point to a relatively low FTS sensitivity of the ERK pathway to Ras inhibition. All of these proteins are essential for the proliferation, growth, and survival of myelomas [1,8,34]. Earlier results showed that chronically active Ras, in cooperation with Myc, facilitates cell-cycle progression while at the same time inhibiting stress responses. Both phenomena are disrupted by Ras inhibition $[26,35]$.

\section{FTS downregulates FGFR3 protein and inhibits FGF-induced NRas activation in NCIH929 cells}

Gene-expression patterns of control and of FTS-treated NCIH929 cells were described in an earlier study [26]. Among the previously reported genes whose expression was altered, we noted a specific decrease in FGFR3 expression by NCIH929 cells [26]. Those findings prompted us to examine the expression of FGFR3 in these cells under the influence of FTS in the present study. Notably, overexpression of

A
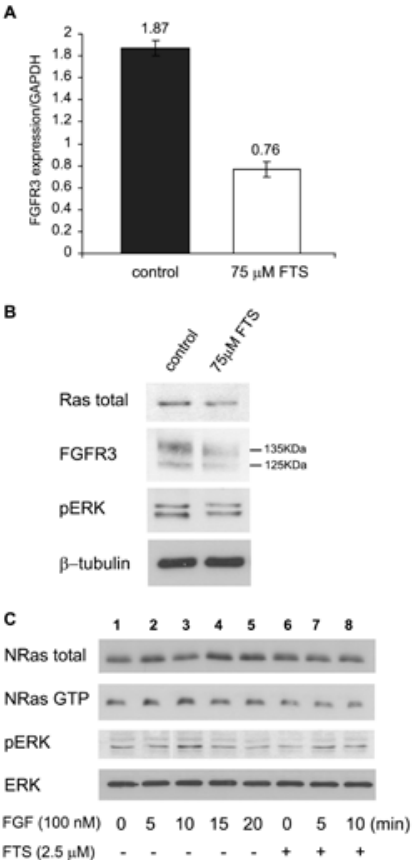

Figure 2: FTS reduces FGFR3 and active ERK in NCIH929 cells. Cells (1 $\times 10^{6} \mathrm{cells} / \mathrm{ml}$ ) were grown in $5 \%$ medium for $72 \mathrm{~h}$ in the absence or in the presence of $75 \mu \mathrm{M}$ FTS (A,B). (A) Cells were harvested and prepared for RT-PCR, as described previously [35]. Samples were quantitatively analyzed for FGFR3 mRNA relative to the housekeeping gene GAPDH (means $\pm \mathrm{SD}, n$ $=3$ for control and FTS). (B) Cell lysates were subjected to SDS-PAGE and immunoblotting with anti-Ras, anti-FGFR3, anti-pERK and anti- $\beta$-tubulin Abs. Typical immunoblots visualized by ECL are shown. FTS reduced FGFR3 by $36 \pm 5 \%$ (mean $\pm \mathrm{SD}, n=3$ ). FGF stimulation increased the amounts of active NRas and pERK in NCIH929 cells and was inhibited by FTS. (C) Cells $\left(210^{6}\right.$ cells $/ \mathrm{ml}$ ) were plated, starved of serum for $48 \mathrm{~h}$, and then stimulated with FGF $(100 \mathrm{nM})$ every $5 \mathrm{~min}$ for $20 \mathrm{~min}$ in the absence and in the presence of 2.5 $\mu \mathrm{M}$ FTS (added $24 \mathrm{~h}$ after the beginning of starvation). The cells were then lysed. Ras activity was determined by a GTP-Ras pull-down assay followed by western blotting with anti-NRas antibody. NRas, pERK, and ERK were quantitatively analyzed by western blotting. Typical immunoblots visualized by ECL are shown $(n=3)$. The difference between the baseline pERK (Figure $2 \mathrm{C}$, lane 1 ) and FGF-stimulated pERK (Figure $2 \mathrm{C}$ lane $3, P<0.05 n=3$ ) and between this value and the FTS inhibition of the FGF-stimulated pERK (Figure $2 \mathrm{C}$ lane $8, P<0.05 n=3$ ) were significant.
FGFR3 is a typical feature of MM [9,14]. In our previous gene-profiling experiments [26] we also observed changes related to other known abnormalities seen in MM.

Next, using real-time PCR we examined the apparent change in expression of FGFR3 after FTS treatment. In NCIH929 cells treated with $75 \mu \mathrm{M}$ FTS, expression of this gene was found to be reduced by $2.44-$ fold relative to the control (Figure 2A). We assume that Ras inhibition reduces transcription of FGFR3, and thus results in reduction in the FGFR3 protein content of these cells (Figure 2B). Because FGFR3 acts through the MAP-kinase pathway $[13,36]$ and thus can activate ERK, we then examined whether FTS treatment also affects MAP kinase in FTS-treated NCIH929 cells. Figure 2B shows that FTS indeed induced a decrease in active ERK. The FTS-induced decrease in ERK could be the result of inhibition of the active NRas, a decrease in the FGF3induced activation of wt NRas, or both. We next examined each of these possibilities.

To establish that active Ras and FGFR3 can act together in myeloma, we assayed NRas-GTP and p-ERK in NCIH929 cells that had been starved of serum for $48 \mathrm{~h}$ and then stimulated with FGF (100 nM) every $5 \mathrm{~min}$ for $20 \mathrm{~min}$ in the absence or in the presence of $2.5 \mu \mathrm{M}$ FTS. The results showed that FGF causes a transient increase in both NRas-GTP and pERK, with a peak at $10 \mathrm{~min}$ (Figure 2C, lane 3). The increase in pERK, although relatively small, was statistically significant $(37.8 \pm 3 \%$, mean \pm SD, $n=3 ; P<0.05)$. As noted, at zero time the NCIH929 cells were already exhibiting a relatively high level of NRas-GTP because they carry one allele of oncogenic NRas [11,12]. Therefore, the FGFinduced increase in NRas-GTP was presumably a result of activation of the wt NRas allele product. The difference between the baseline pERK (Figure 2C, lane 1) and the FGF-stimulated pERK (Figure 2C, lane 3, $n=3$ ), as well as the difference between the latter value and the value obtained after inhibition by FTS of the FGF-stimulated pERK (Figure $2 \mathrm{C}$, lane $8,45 \pm 3.1 \%$ : means $\pm \mathrm{SD}, n=3)$, were significant $(P<0.05$ in both cases).

These findings suggested that FGFR3 acts together with NRas to activate the MAPK pathway, pointing to the possibility that treatment with FTS in combination with FGFR3 inhibitors or other related cytotoxic drugs could be beneficial for patients with MM. Effect of FTS combined with cytotoxic drugs and the impact
of new FTS derivatives on NCIH929 cell growth

Based on the above possibilities, we decided to examine the effects of the combined application of FTS and other inhibitors already in clinical use for the treatment of MM. Proteasome inhibitors have emerged as powerful tools for inhibiting NFkB activity in myelomas [2]. As mentioned in the Introduction, NF- $\kappa B$ plays a powerful role in conferring resistance to apoptosis and chemotherapy [37]. The clinically used proteasome inhibitor bortezomib (Velcade), for example, inhibits the adhesion of MM cells to the stroma, an effect that can be explained, at least in part, by its inhibition of NF- $\kappa B$ [37]. We therefore examined the combined effect of FTS and the proteasome inhibitor MG132 on the growth of NCIH929 cells. First we treated the cells with MG132 alone, and found a dose-dependent reduction in the number of viable cells with a strong effect observed over the concentration range of 2.5-5.0 $\mu \mathrm{M}$ (Figure 3A, insert). We next examined the combined effect of FTS $(50$ or $75 \mu \mathrm{M})$ and MG132 $(0.5,1.0$, or $2.5 \mu \mathrm{M})$ on NCIH929 cell growth. The results clearly indicated a synergistic effect of FTS and MG132, observed particularly with 50 or $75 \mu \mathrm{M}$ FTS and $2.5 \mu \mathrm{M}$ MG132 (Figure 3A). The treatment by FTS reduced cell growth to 
Citation: Yaari-Stark S, Nevo-Caspi Y, Jacob-Hirsch J, Rechavi G, Nagler A, et al. (2011) Combining the Ras Inhibitor Salirasib and Proteasome Inhibitors: A Potential Treatment for Multiple Myeloma. J Cancer Sci Ther 3: 187-194. doi:10.4172/1948-5956.1000086

$91.2 \pm 10.2 \%$ and by MG132 $(2.5 \mu \mathrm{M})$ to $51.5 \pm 22.5 \%$. The expected combined effect was $91.2 \times 51.5 / 100=46.9 \pm 7.2 \%$. The experimentally obtained value of the combined effects of the two drugs was however $32.2 \pm 9.8 \%$ (Figure $3 \mathrm{~A}$ ), indicating synergistic interaction. We also
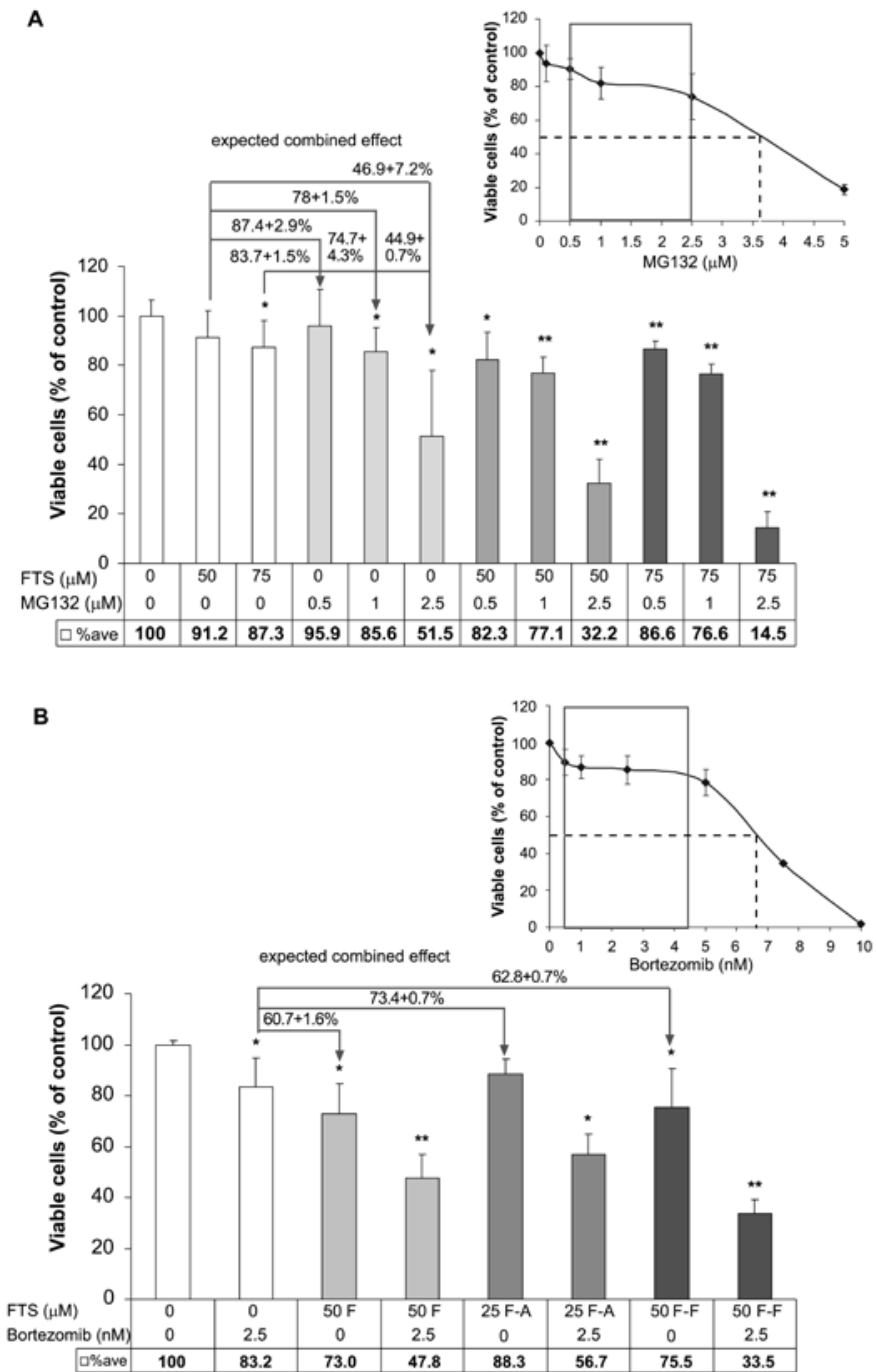

Figure 3: Effects of FTS combined with proteasome inhibitors on NClH929 cell growth. (A) NClH929 cells $\left(1.5 \times 10^{6}\right.$ cells in 24 -well plates) were plated in $5 \%$ FCS medium and treated with $0.1 \%$ DMSO (control) or the indicated concentration of MG132 for $30 \mathrm{~min}$. They were then washed and treated with FTS $(50$ or $75 \mu \mathrm{M})$ or the vehicle $(0.1 \%$ DMSO) for a further 3 days and then counted (at $530 \mathrm{ex} / 590 \mathrm{em}$ ) with the aid of the alamarBlue reagent. Inset: Shown are the numbers of cells in MG132-treated samples, calculated as a percentage of the total number of cells in the control (means $\pm \mathrm{SD}, n=3)$. Highlighted blocks in the box record the concentrations at which the effect of MG132 alone was moderate; the IC $\mathrm{IC}_{50}$ is also marked. (B) $\mathrm{NCIH} 929$ cells $\left(0.5 \times 10^{6}\right.$ in 24-well plates) were plated in $5 \%$ FCS medium and treated with $0.1 \%$ DMSO (control) or with the indicated concentration of FTS or FTS-derivatives (F, FTS; F-A, FTS-amide; F-F, 5-fluoro-FTS) in combination with bortezomib ( $2.5 \mathrm{nM}$ ) for a further 3 days and counted (at $530 \mathrm{ex} / 590 \mathrm{em}$ ) with the aid of the alamarBlue reagent. Inset: Shown are the numbers of cells in bortezomib-treated samples, calculated as a percentage of the total number of cells in the control (means $\pm S D, n=3$ ). Highlighted blocks in the box record the concentrations at which the effect of bortezomib alone was moderate, the $\mathrm{IC}_{50}$ is also marked. Numbers of cells in the drugtreated cultures are expressed as percentages of the numbers recorded in the zero-drug (vehicle-treated) controls. Data are means of three experiments. ${ }^{*} P$ $<0.05,{ }^{* *} P<0.001$, Mann-Whitney U test. calculated the expected $\mathrm{SD}$ as follows : $\mathrm{SD}$ (expected effect) $=[\mathrm{SD}$ (effect of drug $A)^{2} \times\left[S D(\text { effect of drug B })^{2}\right]+\left[S D(\text { effect of drug } A)^{2} \times(\right.$ Effect of drug $\left.B)^{2}\right]+\left[\operatorname{SD}(\text { effect of drug B })^{2} \times(\text { Effect of drug } A)^{2}\right]($ Figure 3,4$)$.

We repeated these experiments with bortezomib and FTS or with the FTS derivatives F-FTS and FTS-A and obtained similar results (Figure $3 \mathrm{~B}$ ). Note that the $\mathrm{IC}_{50}$ of MG132 alone was $3.7 \mu \mathrm{M}$ and that of bortezomib alone was $6.6 \mathrm{nM}$, indicating a much higher potency of the latter drug (Figure 3A and B, inserts). The synergistic effects of bortezomib combined with FTS or with the FTS derivatives were apparent in these experiments too. For example, FTS alone $(50 \mu \mathrm{M})$ reduced cell growth to $73 \pm 11.3 \%$, bortezomib $(2.5 \mathrm{nM})$ reduced cell growth to $83.2 \pm 11.6 \%$, and the expected combined effect was $60.7 \pm$ $1.6 \%$. The experimentally obtained value of the combined effect of the two drugs was however $47.8 \pm 8.9 \%$, indicating synergistic interaction (Figure 3B).

In separate experiments we examined the effect of treatment with FTS combined with doxorubicin $[2,19,38,39]$, another cytotoxic drug used in MM treatment. Treatment of NCIH929 cells with FTS (50 or $75 \mu \mathrm{M})$ combined with doxorubicin $(0.1,0.25$, or $0.5 \mu \mathrm{M}$, Figure $4 \mathrm{~A}$; see also insert) also produced a synergistic effect (calculations were as described above)

Finally, we examined the possibility that some new FTS derivatives exhibit higher potencies than the above-tested compounds in inhibiting MM cell growth. The compounds tested were FTS esters and amides that were recently designed and used experimentally in our laboratory [40]. We treated NCIH929 with various concentrations of FTS-methyl ester, FTS-ethyl ester, FTS-methoxymethyl ester, FTS-amide, and FTS-methyl amide. The results are shown in Figure 4B. An interesting finding was that whereas the FTS-esters were completely inactive, the FTS-amides exhibited significantly higher activity (50\% higher) than FTS itself. FTS-amides might therefore be worth considering as a potential treatment for MM.

\section{Discussion}

The most common mutation in MM is in Ras genes [8], with an estimated $30 \%$ to $50 \%$ of all myelomas exhibiting mutations in NRas or KRas $[3,8]$. NCIH929 cells harbor an oncogenic NRas(13V) allele and an amplified $c-M y c$ gene, and thus represent a typical incurable MM. Here we show that NCIH929 cells exhibit relatively high expression of active NRas-GTP compared to other myeloma cell lines, which are characterized by low expression of NRas protein or do not express oncogenic NRas $[4,41]$. NRas-GTP expression levels were found here to be decreased by the Ras inhibitor FTS (Figure 1B). Our results also showed that growth inhibition by FTS is stronger in NCIH929 cells than in the other two cell lines tested (Figure 1A). This finding was consistent with the reported mode of action of FTS, as found in numerous tumor cell lines that harbor activated Ras, including panc-1 pancreatic cancer, SW480 colon carcinomas, and 518A2 melanomas [31-33]. Because of this apparent selectivity of FTS toward active Ras, the growth of cells with chronically active Ras (such as glioblastoma [42], neuroblastoma with amplified $M y c N$ [35], and melanomas [33] is inhibited by FTS, while untransformed cells are affected less strongly.

Another notable finding of the present study was the marked impact of FTS on FGFR3, a tyrosine kinase receptor which is a critical requirement for the proliferation and survival of MM tumor cells $[9,14]$. FTS reduced the expression levels of FGFR3 and its protein (Figure 2A, B). Previous gene expression analysis showed small decreases in the 
expression of histone deacetylase $H D A C$ genes [26], which affect MM cell growth [43], and in the expression of Xbp1, which itself is marker for poor prognosis for MM [10]. An increase in expression of the proapoptotic gene Bax was also reported [43].

Our results showed that FTS, through its action on active NRas, exerts multiple effects which, when taken together, at least partially reverse the malignant phenotype of NCIH929 cells. FTS rapidly reduced both oncogenic NRas(13V)-GTP (present in cells without FGF stimulation) and FGF-stimulated NRas-GTP loading (Figure 1B, 2C). In this way treatment with FTS led to inhibition of ERK activation, presumably through inhibition of the typical Ras-dependent Raf/MEK/ ERK MAPK cascade (Figure 2B). These findings and the inhibition of Akt, along with the consequent long-term effects on gene expression including the negative impact on FGFR3, support the notion that FTS
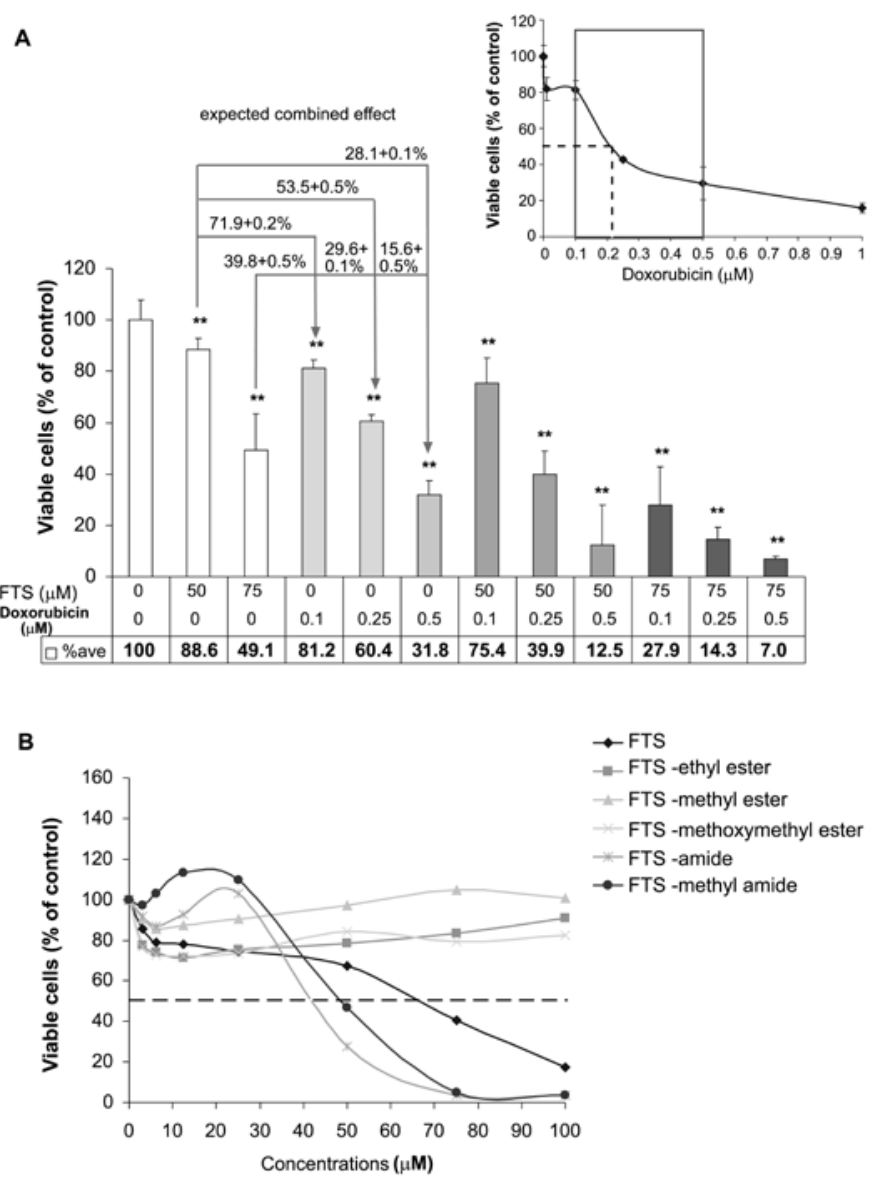

Figure 4: Effects of FTS in combination with cytotoxic drugs or new FTS derivatives on NCIH929 cell growth. (A) NCIH929 cells $(150,000$ cells in 96 -well plates) were plated in 5\% FCS medium and then treated with FTS (50 or $75 \mu \mathrm{M})$ or vehicle $(0.1 \%$ DMSO) combined with the indicated concentration of doxorubicin, and incubated for 5 days. Live cells were counted with the aid of the alamarBlue reagent. Inset: Shown are the numbers of cells in doxorubicin-treated samples, calculated as a percentage of the total number of cells in the control (means $\pm \mathrm{SD}, n=3$ ). Numbers of cells in the drug-treated cultures are expressed as percentages of the numbers recorded in the zero drug (vehicle-treated) controls. Data are means of three experiments. ${ }^{*} P<$ $0.05,{ }^{* *} P<0.001$, Mann-Whitney U test. (B) NCIH929 cells $(150,000$ cells in 96 -well plates) were plated in $5 \%$ FCS medium containing the drug at its final concentration. FTS derivates were dissolved in DMSO and diluted with $5 \%$ FCS medium to the indicated concentrations. Control cells received the vehicle $(0.1 \% \mathrm{DMSO})$. Cells viability was determined after 4 days with the aid of the alamarBlue reagent. Data are means of three experiments. is a rational candidate for the treatment of MM. In this regard, the relatively high potency of FTS-amide, a novel derivative, suggests that this new compound might be even more efficacious than FTS in MM.

The above suggestions must be viewed in light of the knowledge that although $\mathrm{MM}$ is responsive to first-line chemotherapy, most patients relapse and die from their disease [1]. Given the poor survival of MM patients, the introduction of new targeted drugs is of utmost importance. Many attempts have indeed been made to develop such drugs for MM therapy.

Groups of drugs used clinically or in clinical trials include thalidomide (Thalomid; Celgene Corporation, Summit, NJ) and its analog lenalidomide (Revimid), as well as bortezomib (Velcade [formerly PS-341]) and its analogs (Millennium Pharmaceuticals, Cambridge, MA), and farnesyl transferase inhibitors, which were originally designed as Ras inhibitors [8,21]. Most of these drugs have failed to increase survival rates to any great extent [2], emphasizing the need for new targeted nontoxic drugs for the treatment of MM.

Based on the results of the present study, we propose the use of FTS combined with proteasome inhibitors (Figure 3A) for MM treatment. Our results indicate a synergistic effect of FTS and bortezomib on growth inhibition and cell death. The dependence of MM on NF$\kappa \mathrm{B}$ expression and the high rates of IgG synthesis appear to render these cancer cells sensitive to bortezomib $[2,4]$. Interestingly, loss of p53 and a concomitant oncogenic activation of KRas were recently shown to lead to activation of NF- $\kappa \mathrm{B}$ in mouse embryonic fibroblasts [44]. Moreover, the addition of p53 to lung cancer cells expressing oncogenic KRAS and lacking p53 resulted in NF- $\kappa B$ inhibition [44]. Another study demonstrated the need for IкB kinase (TBK1) and NF$\kappa \mathrm{B}$ signaling in oncogenic KRas tumors [45]. These studies broaden our understanding of the association between oncogenic Ras and NF- $\mathrm{BB}$ activation, and are in line with our present observation of a synergistic effect between the inhibition of active Ras by FTS and the reduction in NF- $\kappa$ B by bortezomib. The dependence of MM on FGFR3 and Ras pathways makes these pathways sensitive to Ras inhibitors such as FTS. The synergistic effects of bortezomib and FTS in NCIH929 cells, and presumably in $\mathrm{MM}$, might be explained by the two distinct pathways that they affect.

Bortezomib has already been approved for MM, while FTS has successfully passed phase I and II trials in pancreatic and lung cancer patients with minimal adverse side effects (http://www. concordiapharma.com/index.htm). It seems, therefore, that combining the two drugs for MM treatment is feasible. This possibility might add a useful newcomer to the novel FGFR3-inhibitory drugs for MM, including vorinostat (Merck) and panobinostat (LBH-589; Novartis), which are HDAC inhibitors, and are currently undergoing clinical trials.

\section{Acknowledgments}

The authors would like to thank the Naor family for a generous research grant memorializing their late son-in-law, Guy Weinstock. We would also like to thank The Guy Weinstock Multiple Myeloma Foundation for its support of research on the field of multiple myeloma at the Division of Hematology, Chaim Sheba Medical Center, Tel Hashomer. The authors would also like to thank Shirley Smith for editorial assistance.

This work was supported by the Israel Science Foundation (Grant no. 912/06 to Y.K). Yoel Kloog is the incumbent of The Jack H. Skirball Chair for Applied Neurobiology and Head of the Prajs-Drimmer Institute for The Development of Anti-Degenerative Drugs, which supported the work of S.Y.-S. This study was also 
supported in part by a Jacqueline Seroussi Memorial Foundation grant award (to A.N.).

\section{References}

1. Dai $Y$, Landowski TH, Rosen ST, Dent P, Grant S (2002) Combined treatment with the checkpoint abrogator UCN-01 and MEK1/2 inhibitors potently induces apoptosis in drug-sensitive and resistant myeloma cells through an IL-6independent mechanism. Blood 100: 3333-3343.

2. Saunders $G$ (2005) Overview of drug therapy for multiple myeloma. J Oncol Pharm Pract 11: 83-100.

3. Fonseca R, Barlogie B, Bataille R, Bastard C, Bergsagel PL, et al. (2004) Genetics and cytogenetics of multiple myeloma: a workshop report. Cancer Res 64: 1546-1558.

4. Greenstein S, Krett NL, Kurosawa Y, Ma C, Chauhan D, et al. (2003) Characterization of the MM.1 human multiple myeloma (MM) cell lines: a model system to elucidate the characteristics, behavior, and signaling of steroidsensitive and -resistant MM cells. Exp Hematol 31: 271-282.

5. Hardan I, Rothman R, Gelibter A, Cohen N, Shimoni A, et al. (2004) Determination of chromosome 13 status in bone marrow cells of patients with multiple myeloma using combined morphologic and fluorescence in situ hybridization analysis. Exp Hematol 32: 254-260.

6. Koren-Michowitz M, Hardan I, Berghoff J, Yshoev G, Amariglio N, et al. (2007) Chromosome $13 \mathrm{q}$ deletion and $\mathrm{IgH}$ abnormalities may be both masked by near-tetraploidy in a high proportion of multiple myeloma patients: a combined morphology and I-FISH analysis. Cancer Lett 255: 307-314.

7. Trakhtenbrot L, Hardan I, Koren-Michowitz M, Oren S, Yshoev G, et al. (2010) Correlation between losses of IGH or its segments and deletions of 13q14 in $\mathrm{t}(11 ; 14)$ (q13;q32) multiple myeloma. Genes Chromosomes Cancer 49: 17-27.

8. Santucci R, Mackley PA, Sebti S, Alsina M (2003) Farnesyltransferase inhibitors and their role in the treatment of multiple myeloma. Cancer Control 10: 384-387.

9. Dalton WS, Bergsagel PL, Kuehl WM, Anderson KC, Harousseau JL (2001) Multiple myeloma. Hematology Am Soc Hematol Educ Program 157-177.

10. Hideshima T, Bergsagel PL, Kuehl WM, Anderson KC (2004) Advances in biology of multiple myeloma: clinical applications. Blood 104: 607-618.

11. Chesi M, Nardini E, Brents LA, Schrock E, Ried T, et al. (1997) Frequent translocation $\mathrm{t}(4 ; 14)(\mathrm{p} 16.3 ; \mathrm{q} 32.3)$ in multiple myeloma is associated with increased expression and activating mutations of fibroblast growth factor receptor 3. Nat Genet 16: 260-264.

12. Chesi M, Nardini E, Lim RS, Smith KD, Kuehl WM, et al. (1998) The $t(4: 14)$ translocation in myeloma dysregulates both FGFR3 and a novel gene, MMSET, resulting in IgH/MMSET hybrid transcripts. Blood 92: 3025-3034.

13. Chesi M, Brents LA, Ely SA, Bais C, Robbiani DF, et al. (2001) Activated fibroblast growth factor receptor 3 is an oncogene that contributes to tumor progression in multiple myeloma. Blood 97: 729-736.

14. Zhu L, Somlo G, Zhou B, Shao J, Bedell V, et al. (2005) Fibroblast growth factor receptor 3 inhibition by short hairpin RNAs leads to apoptosis in multiple myeloma. Mol Cancer Ther 4: 787-798.

15. El-Cheikh J, Michallet M, Nagler A, de Lavallade H, Nicolini FE, et al. (2008) High response rate and improved graft-versus-host disease following bortezomib as salvage therapy after reduced intensity conditioning allogeneic stem cell transplantation for multiple myeloma. Haematologica 93: 455-458.

16. Kneller A, Raanani P, Hardan I, Avigdor A, Levi I, et al. (2000) Therapy with thalidomide in refractory multiple myeloma patients - the revival of an old drug. Br J Haematol 108: 391-393.

17. Kroger N, Badbaran A, Lioznov M, Schwarz S, Zeschke S, et al. (2009) Posttransplant immunotherapy with donor-lymphocyte infusion and novel agents to upgrade partial into complete and molecular remission in allografted patients with multiple myeloma. Exp Hematol 37: 791-798.

18. Kroger N, Shimoni A, Zagrivnaja M, Ayuk F, Lioznov M, et al. (2004) Low-dose thalidomide and donor lymphocyte infusion as adoptive immunotherapy after allogeneic stem cell transplantation in patients with multiple myeloma. Blood 104: 3361-3363
19. Sonneveld P, Hajek R, Nagler A, Spencer A, Blade J, et al. (2008) Combined pegylated liposomal doxorubicin and bortezomib is highly effective in patients with recurrent or refractory multiple myeloma who received prior thalidomide/ lenalidomide therapy. Cancer 112: 1529-1537.

20. van de Donk NW, Kroger N, Hegenbart U, Corradini P, San Miguel JF, et al. (2006) Remarkable activity of novel agents bortezomib and thalidomide in patients not responding to donor lymphocyte infusions following nonmyeloablative allogeneic stem cell transplantation in multiple myeloma. Blood 107: 3415-3416.

21. Bolick SC, Landowski TH, Boulware D, Oshiro MM, Ohkanda J, et al. (2003) The farnesyl transferase inhibitor, FTI-277, inhibits growth and induces apoptosis in drug-resistant myeloma tumor cells. Leukemia 17: 451-457.

22. Sharan R, Shamir R (2000) CLICK: a clustering algorithm with applications to gene expression analysis. Proc Int Conf Intell Syst Mol Biol 8: 307-316.

23. Shamir R, Maron-Katz A, Tanay A, Linhart C, Steinfeld I, et al. (2005) EXPANDER--an integrative program suite for microarray data analysis. BMC Bioinformatics 6: 232.

24. Elkon R, Linhart C, Sharan R, Shamir R, Shiloh Y (2003) Genome-wide in silico identification of transcriptional regulators controlling the cell cycle in human cells. Genome Res 13: 773-780.

25. Blum R, Elkon R, Yaari S, Zundelevich A, Jacob-Hirsch J, et al. (2007) Gene Expression Signature of Human Cancer Cell Lines Treated with the Ras Inhibitor Salirasib (S-Farnesylthiosalicylic Acid). Cancer Res 67: 3320-3328.

26. Yaari-Stark S, Shaked M, Nevo-Caspi $Y$, Jacob-Hircsh J, Shamir R, et al. (2010) Ras inhibits endoplasmic reticulum stress in human cancer cells with amplified Myc. Int J Cancer 126: 2268-2281.

27. Rotblat B, Ehrlich M, Haklai R, Kloog Y (2008) The Ras inhibito farnesylthiosalicylic acid (Salirasib) disrupts the spatiotemporal localization of active Ras: a potential treatment for cancer. Methods Enzymol 439: 467-489.

28. Greco WR, Bravo G, Parsons JC (1995) The search for synergy: a critical review from a response surface perspective. Pharmacol Rev 47: 331-385.

29. Elad-Sfadia G, Haklai R, Ballan E, Gabius HJ, Kloog Y (2002) Galectin-1 augments Ras activation and diverts Ras signals to Raf-1 at the expense of phosphoinositide 3-kinase. J Biol Chem 277: 37169-37175.

30. Herrmann C, Martin GA, Wittinghofer A (1995) Quantitative analysis of the complex between p21ras and the Ras-binding domain of the human Raf-1 protein kinase. J Biol Chem 270: 2901-2905

31. Weisz B, Giehl K, Gana-Weisz M, Egozi Y, Ben-Baruch G, et al. (1999) A new functional Ras antagonist inhibits human pancreatic tumor growth in nude mice. Oncogene 18: 2579-2588.

32. Gana-Weisz M, Halaschek-Wiener J, Jansen B, Elad G, Haklai R, et al. (2002) The Ras inhibitor S-trans,trans-farnesylthiosalicylic acid chemosensitizes human tumor cells without causing resistance. Clin Cancer Res 8: 555-565.

33. Jansen B, Schlagbauer-Wadl H, Kahr H, Heere-Ress E, Mayer BX, et al. (1999) Novel Ras antagonist blocks human melanoma growth. Proc Natl Acad Sci U S A 96: 14019-14024.

34. Shou Y, Martelli ML, Gabrea A, Qi Y, Brents LA, et al. (2000) Diverse karyotypic abnormalities of the c-myc locus associated with c-myc dysregulation and tumor progression in multiple myeloma. Proc Natl Acad Sci U S A 97: 228-233.

35. Yaari S, Jacob-Hirsch J, Amariglio N, Haklai R, Rechavi G, et al. (2005) Disruption of cooperation between Ras and $\mathrm{MycN}$ in human neuroblastoma cells promotes growth arrest. Clin Cancer Res 11: 4321-4330.

36. Eswarakumar VP, Lax I, Schlessinger J (2005) Cellular signaling by fibroblast growth factor receptors. Cytokine Growth Factor Rev 16: 139-149.

37. Rajkumar SV, Richardson PG, Hideshima T, Anderson KC (2005) Proteasome inhibition as a novel therapeutic target in human cancer. J Clin Oncol 23: 630639

38. Orlowski RZ, Nagler A, Sonneveld P, Blade J, Hajek R, et al. (2007) Randomized phase III study of pegylated liposomal doxorubicin plus bortezomib compared 
Citation: Yaari-Stark S, Nevo-Caspi Y, Jacob-Hirsch J, Rechavi G, Nagler A, et al. (2011) Combining the Ras Inhibitor Salirasib and Proteasome Inhibitors: A Potential Treatment for Multiple Myeloma. J Cancer Sci Ther 3: 187-194. doi:10.4172/1948-5956.1000086

with bortezomib alone in relapsed or refractory multiple myeloma: combination therapy improves time to progression. J Clin Oncol 25: 3892-3901.

39. Blade J, Sonneveld P, San Miguel JF, Sutherland HJ, Hajek R, et al. (2008) Pegylated liposomal doxorubicin plus bortezomib in relapsed or refractory multiple myeloma: efficacy and safety in patients with renal function impairment. Clin Lymphoma Myeloma 8: 352-355.

40. Goldberg L, Haklai R, Bauer V, Heiss A, Kloog Y (2009) New derivatives of farnesylthiosalicylic acid (salirasib) for cancer treatment: farnesylthiosalicylamide inhibits tumor growth in nude mice models. J Med Chem 52: 197-205.

41. Dai Y, Chen S, Pei XY, Almenara JA, Kramer LB, et al. (2008) Interruption of the Ras/MEK/ERK signaling cascade enhances Chk1 inhibitor-induced DNA damage in vitro and in vivo in human multiple myeloma cells. Blood 112: 24392449 .
42. Blum R, Jacob-Hirsch J, Amariglio N, Rechavi G, Kloog Y (2005) Ras inhibition in glioblastoma down-regulates hypoxia-inducible factor-1alpha, causing glycolysis shutdown and cell death. Cancer Res 65: 999-1006.

43. Mitsiades CS, Mitsiades NS, McMullan CJ, Poulaki V, Shringarpure R, et al (2004) Transcriptional signature of histone deacetylase inhibition in multiple myeloma: biological and clinical implications. Proc Natl Acad Sci U S A 101 540-545.

44. Barbie DA, Tamayo P, Boehm JS, Kim SY, Moody SE, et al. (2009) Systematic RNA interference reveals that oncogenic KRAS-driven cancers require TBK1. Nature 462: 108-112.

45. Meylan E, Dooley AL, Feldser DM, Shen L, Turk E, et al. (2009) Requirement for NF-kappaB signalling in a mouse model of lung adenocarcinoma. Nature 462: 104-107. 